\title{
Direct Chemical Oxidation of Mixed or Toxic Wastes
}

\author{
John F. Cooper \\ G. Bryan Balazs \\ Patricia Lewis \\ Joseph C. Farmer
}

This paper was prepared for submittal to the

NATO/ISTC Workshop: Environmental Aspects of

Converting CW Facilities to Peaceful Purposes

Spiez, Switzerland

March 10, 1999

May 1999

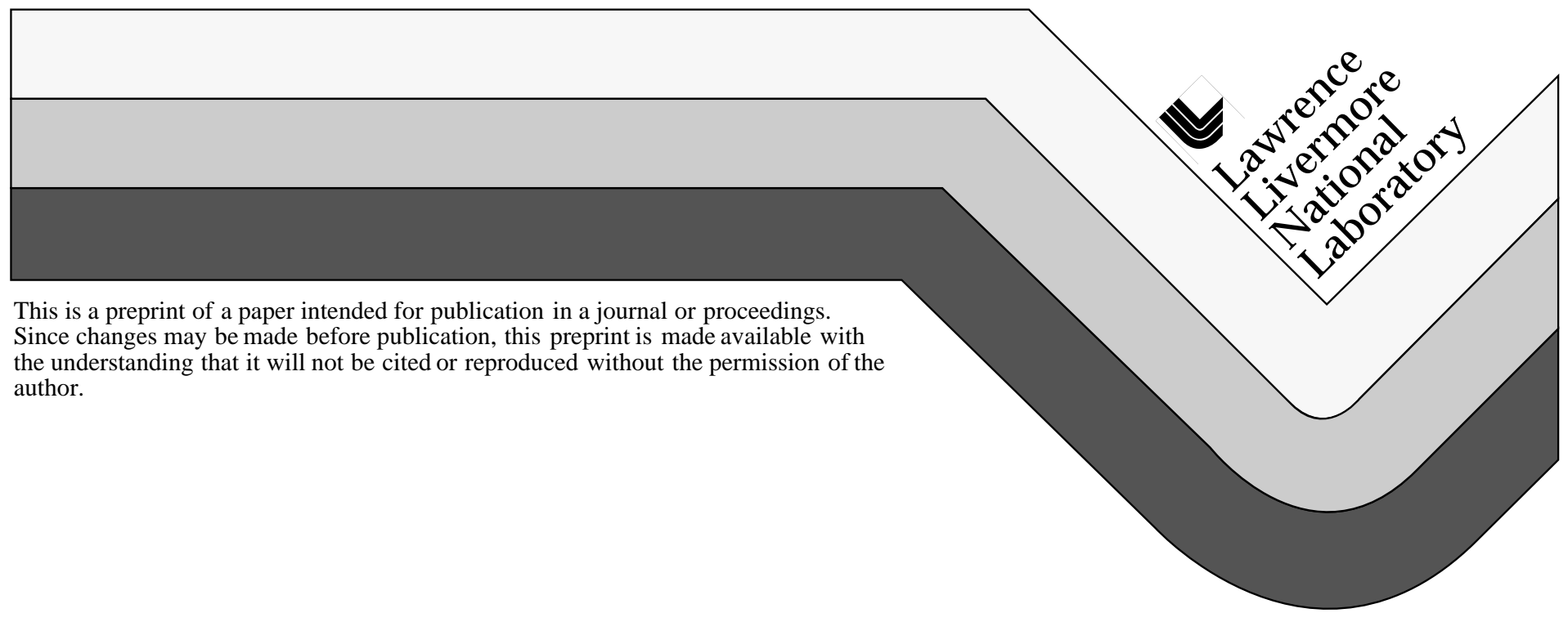




\section{DISCLAIMER}

This document was prepared as an account of work sponsored by an agency of the United States Government. Neither the United States Government nor the University of California nor any of their employees, makes any warranty, express or implied, or assumes any legal liability or responsibility for the accuracy, completeness, or usefulness of any information, apparatus, product, or process

disclosed, or represents that its use would not infringe privately owned rights. Reference herein to any specific commercial product, process, or service by trade name, trademark, manufacturer, or otherwise, does not necessarily constitute or imply its endorsement, recommendation, or favoring by the United States Government or the University of California. The views and opinions of authors expressed herein do not necessarily state or reflect those of the United States Government or the University of California, and shall not be used for advertising or product endorsement purposes. 
Proc. Advanced Research Workshop: Environmental Aspects of Converting CW Facilities to Peaceful Purpose March 10, 1999 Spiez Switzerland

UCRL-JC-134229 Page 1

\title{
DIRECT CHEMICAL OXIDATION OF MIXED OR TOXIC WASTES
}

\author{
John F. Cooper, G. Bryan Balazs, Patricia Lewis and Joseph C. Farmer \\ Chemistry and Materials Science Directorate, L-352 \\ Lawrence Livermore National Laboratory Livermore CA 94550 \\ Tel. (925) 423-6649; Fax (925) 422-0049; email: Cooper3@LLNL.gov
}

\begin{abstract}
Direct Chemical Oxidation (DCO) is an ambient-pressure, low-temperature $\left(<100^{\circ} \mathrm{C}\right)$, and aqueous-based process for general-purpose destruction of the organic fraction of hazardous or mixed waste. It uses the peroxydisulfate anion $\left(\mathrm{S}_{2} \mathrm{O}_{8}{ }^{2-}\right)$ in acid or base solutions. The byproduct of the oxidation reaction, typically sodium or ammonium hydrogen sulfate, may be recycled electrolytically to produce the oxidant. The oxidation kinetic reaction is first order with respect to the peroxydisulfate concentration, expressed in equivalents. The rate constant is constant for nearly all dissolved organic compounds: $\mathrm{k}_{\mathrm{a}}=0.01 \pm 0.005 \mathrm{~min}^{-1}$. This reflects a common rate-determining step, which is the decomposition of the peroxydisulfate anion into the chemically active derivative, the sulfate radical anion, $\mathrm{SO}_{4}{ }^{-}$. This decomposition is promoted in DCO by raising the operating temperature into the range of $80-100{ }^{\circ} \mathrm{C}$. Rates are given for approximately 30 substances with diverse functional groups at low concentrations, and for a number of solid and liquid wastes typical of nuclear and chemical industries. The process has been scale up for treatment studies on chlorinated hydrocarbons, in which the hydrolysis of solvent mixtures was followed by oxidation of products in a series of stirred tank reactors. Cost estimates, safety considerations, and a comprehensive bibliography are given.
\end{abstract}

\section{Introduction}

The Direct Chemical Oxidation Process, "DCO", was developed at Lawrence Livermore National Laboratory (LLNL) with internal R\&D and EM50/MWFA support. It is a nonthermal, low temperature $\left(<100^{\circ} \mathrm{C}\right)$, ambient pressure, aqueous based technology for the oxidative destruction of the organic components of hazardous or mixed waste streams. (Program publications are given in references [1-8], Appendix A). The process uses solutions of sodium or ammonium peroxydisulfate to fully oxidize organic material to carbon dioxide and water. The expended oxidant (sodium or ammonium hydrogen sulfate) may be regenerated by electrolysis to minimize secondary waste or oxidant cost. The net waste treatment reaction is:

$$
\mathrm{S}_{2} \mathrm{O}_{8}{ }^{2-}+\text { (organic) } \Rightarrow 2 \mathrm{HSO}_{4}{ }^{-}+\left(\mathrm{CO}_{2}, \mathrm{H}_{2} \mathrm{O} \text {, inorganic residues }\right)
$$

The peroxydisulfate process is an application of a well-established industrial technology. Acidified ammonium peroxydisulfate is one of the strongest oxidants known. It is comparable to ozone, and exceeded in oxidative power only by fluorine and oxyfluorides. The process is primarily being developed for the treatment of organic liquids and solids contaminated with organic liquids. It will oxidize the organic fraction of sludge if the matrix is finely divided and slurried with the working solution. Destruction of some organic solids, such as paper, cloth, and 
Proc. Advanced Research Workshop: Environmental Aspects of Converting CW Facilities to Peaceful Purpose March 10, 1999 Spiez Switzerland

UCRL-JC-134229 Page 2

styrene resins, is possible, and other plastics and inorganic debris will be partially oxidized and decontaminated. The oxidation potential of peroxydisulfate is high enough to oxidize nearly all organics; thus the process is virtually "omnivorous." However, perfluorinated polymers (e.g. Teflon) are inert, and reactions with polyethylene and PVC are slow, so surface oxidation to decontaminate rather than destroy the matrix is a more practical goal. Many organics are oxidized by the process at ambient pressure and temperatures in the 80 to $100{ }^{\circ} \mathrm{C}$ range. More recalcitrant materials, e.g., PVC polymer benefit from thermal treatment $\left(140-180^{\circ} \mathrm{C}, 24 \mathrm{~h}\right)$ to partially pyrolize the material before oxidation by peroxydisulfate.

At room temperature, solid peroxydisulfate salts and moderately concentrated solutions are stable. The ion is thermally activated at moderate temperatures $\left(>80^{\circ} \mathrm{C}\right)$ to produce the sulfate radical anion (SRA), which is a strong charge transfer agent:

$$
\mathrm{S}_{2} \mathrm{O}_{8}{ }^{2-}=2 \mathrm{SO}_{4}^{-}
$$

This free radical initiates a cascade of oxidation reactions in the organic wastes producing intermediate organic molecular fragments, organic and hydroxyl free radicals, inorganic ions in high oxidation states (e.g., $\mathrm{Ag}$ (II) and $\mathrm{Co}$ (III) if these elements are present), and secondary oxidants such as peroxymonosulfate, hydrogen peroxide, ozone, and nascent oxygen. Reaction [1] can also be catalyzed by UV, transition metal ions, radiolysis, and noble metals. The chemistry is reviewed by House [9], Menisci [10] and Peyton [11]. In general, oxidation by peroxydisulfate in mild acid or base is first order in $\left[\mathrm{S}_{2} \mathrm{O}_{8}{ }^{2}\right]$ and follows the rate equation,

$$
\mathrm{d}[\mathrm{R}] / \mathrm{dt}=-\mathrm{k}_{\mathrm{a}}\left[\mathrm{S}_{2} \mathrm{O}_{8}{ }^{2-}\right]
$$

with $\mathrm{k}_{\mathrm{a}}=0.01-0.02 \mathrm{~min}^{-1}$ when both $[\mathrm{R}]$ and $\left[\mathrm{S}_{2} \mathrm{O}_{8}{ }^{2-}\right]$ are expressed in units of normality (equivalents per liter). Table 1 shows the rates of destruction of a variety of chemicals with diverse functional groups, for initially low concentrations ( $<50 \mathrm{ppm}$, as carbon). Figure 1 shows the temperature dependence of the oxidation rate for dilute and concentrated organics, which extrapolates well from low temperatures for the rate of formation of the SRA. The formation of organic free radicals can accelerate the formation of the SRA, leading to a doubling or tripling in the rate of organic destruction in initially concentrated solutions.

Table I. Integral rate constants (equivalence based) for compounds with diverse functional groups at initial concentrations $<50$ ppm.

\begin{tabular}{|l|c|c|c||l|c|c|c|}
\hline Compound & $\mathrm{M}_{\mathrm{w}}$ & $\mathrm{n}$ & $10^{2} \mathrm{k}_{\mathrm{a}}$ & Compound & $\mathrm{M}_{\mathrm{w}}$ & $\mathrm{n}$ & $10^{2} \mathrm{ka}$ \\
\hline & $\mathrm{g} / \mathrm{mol}$ & $\mathrm{eq} / \mathrm{mol}$ & $1 / \mathrm{min}$ & & $\mathrm{g} / \mathrm{mol}$ & $\mathrm{eq} / \mathrm{mol}$ & $1 / \mathrm{min}$ \\
\hline Urea & 60.06 & 0 & 0.36 & 4-amino-pyridine & 94.12 & 20 & 1.47 \\
\hline oxalic acid dihydrate & 126.00 & 2 & 0.38 & acetic acid & 60.05 & 8 & 1.54 \\
\hline Nitromethane & 61.04 & 8 & 0.63 & sucrose & 342.29 & 48 & 1.55 \\
\hline Salicylate-Na salt & 160.10 & 28 & 0.73 & Methylphosphonic acid & 96.02 & 8 & 1.56 \\
\hline formic acid & 46.03 & 2 & 0.73 & 2,2'-thiodiethanol & 122.18 & 28 & 1.71 \\
\hline Triethylamine & 101.19 & 36 & 0.76 & 1,4-dioxane & 88.11 & 20 & 1.94 \\
\hline DMSO & 78.13 & 18 & 0.79 & ethylene glycol & 62.07 & 10 & 1.95 \\
\hline DIMP & 180.18 & 44 & 1.26 & formamide & 45.04 & 5 & 2.01 \\
\hline Na-EDTA & 372.24 & 39 & 1.34 & Na-lauryl sulfate & 288.38 & 72 & 2.32 \\
\hline 4-chloropyridine HCl & 150.01 & 21 & 1.43 & & & & \\
\hline
\end{tabular}


Proc. Advanced Research Workshop: Environmental Aspects of Converting CW Facilities to Peaceful Purpose March 10, 1999 Spiez Switzerland

UCRL-JC-134229 Page 3

aConditions: $\mathrm{T}=100^{\circ} \mathrm{C} ;\left[\mathrm{H}_{3} \mathrm{PO} 4\right]=0.0574 \mathrm{M} ;\left[\mathrm{S}_{2} \mathrm{O}_{8}{ }^{-2}\right]=0.245 \mathrm{~N} ; 0.3 \mathrm{~cm}^{2} \mathrm{Pt}$ wire catalysis.

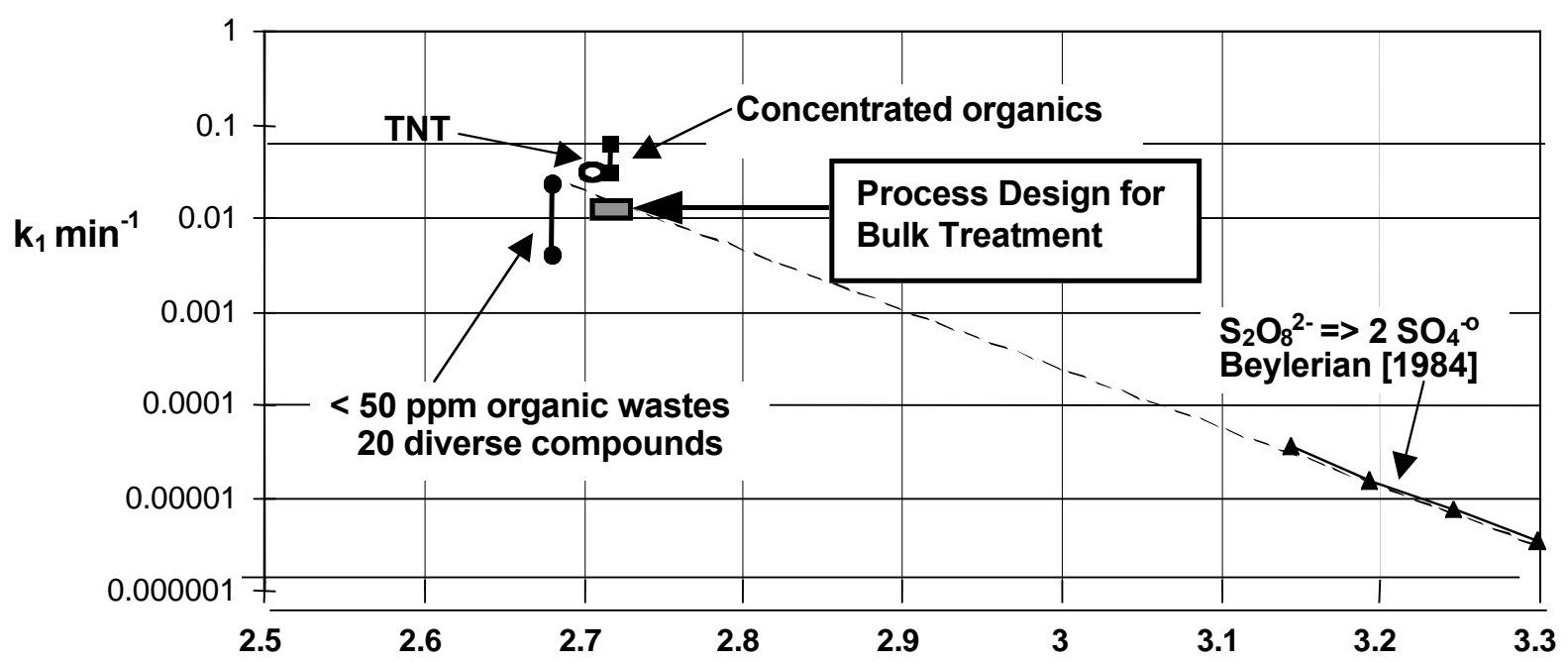

$1000 /(T+273.16)$

Figure 1. The domain of operation of DCO at $\mathrm{T}=90-100^{\circ} \mathrm{C}$ falls on the extrapolated rate of formation of the sulfate radical anion. More concentrated organics are destroyed at higher rates than dilute organics (concentrations $<50 \mathrm{ppm}$ ), because of the accelerating effect of intermediate free radicals on peroxydisulfate activation.

Phosphorus, sulfur, and amino nitrogen groups are converted to their oxyanions. Ammonium ion and perfluorinated polymers $\left(\mathrm{CF}_{\mathrm{x}}\right)$ are not oxidized. Organic compounds are attacked preferentially to water and to functional or free chloride ions. At temperatures below $100^{\circ} \mathrm{C}$, amorphous carbon, polyethylene and polyvinyl chloride plastics are slowly attacked. The rate of oxidation (governed by rate of formation of SRA) is independent of $\mathrm{pH}$ above $\mathrm{pH}=1$. Basic solutions are favored for treatment of halide-rich compounds such as chlorinated solvents or PCB's, because chlorine remains in the $\mathrm{Cl}^{-}$state due to the shift of the chloride-hydroxylradical equilibrium [11],

$$
\mathrm{Cl}^{\circ}+\mathrm{OH}^{-}=\mathrm{Cl}^{-}+\mathrm{OH}^{\circ}
$$

The steady-state concentration and half-life of the SRA is exceedingly small and the meanfree path of the SRA is also very short. This means that the peroxydisulfate oxidant is very effective when pumped as a concentrated solution into porous media such as soils, filters, or sand - allowing the SRA to be formed in situ at the point of use. Indeed destruction of PCB's and pesticides in soil or sand media has been demonstrated elsewhere (R. Pugh, [13]). We found no difference in the destruction rates of common surrogates (such as dichloropropanol, ethylene glycol, or phenol) in well-mixed solutions compared with slurried sludge, sand or clay formulations. 
Proc. Advanced Research Workshop: Environmental Aspects of Converting CW Facilities to Peaceful Purpose March 10, 1999 Spiez Switzerland

UCRL-JC-134229 Page 4

\section{Status of the Technology}

The DCO process was developed for applications in waste treatment, chemical demilitarization and decontamination, and environmental remediation by engineers and scientists at Lawrence Livermore National Laboratory, beginning in 1992. The integrated DCO process (including hydrolysis) was demonstrated on the pilot-plant scale (15 kg/day, as carbon), using LLNL waste streams or surrogates containing chlorinated solvents. A broad spectrum of materials has been successfully oxidized using peroxydisulfate, including: acetic acid, formamide, ethylene glycol, tributyl phosphate, trialkyl amines, kerosene, methyl chloroform, trinitrotoluene and other explosives, surrogates for biological or chemical warfare agents, paper and cotton, PCB's, pentachlorophenol, ion exchange resins (DOWEX), and carbon residuals found in simulated sludge. Further research is not deemed necessary prior to scale-up for implementation, but treatability studies should be undertaken on each candidate waste stream to ensure processability.

General conclusions based on demonstration testing to date are:

1. Chlorinated materials are readily destroyed by peroxydisulfate. Pre-hydrolysis is not necessary for oxidation, but enhances contaminant solubility, and avoids the complexities of pressurizing the oxidation step (with $\mathrm{CO}_{2}$ evolution) to avoid entrainment of the volatile solvents in the $\mathrm{CO}_{2}$ offgas. Dilute pentachlorophenol and PCBs are also fully oxidized in basic DCO media.

2. Testing in larger equipment with trichloroethane supports the premise that the process can be readily scaled up to desired production throughput.

3. Complete oxidation of non-cellulostic debris is possible but is generally too slow and requires too much oxidant to support a practical throughput. Decontamination of these materials by surface oxidation is a more practical goal.

4. The composition of the offgas stream will depend on the particular waste being processed, but will typically include carbon dioxide from the oxidation of organic matter, and some oxygen produced by a minor competing side reaction (oxidation of water). In acid solutions, some chlorine will be present in the offgas resulting from oxidation of chlorine-containing wastes, but use of DCO in alkaline solutions avoids the formation of chlorine and chlorine released from organic molecule or free inorganic chloride remains as the chloride ion in solution.

5. At the process operating conditions, formation of dioxins and furans in the offgas is not believed possible, and analyses to check for these materials have been negative.

6. Wastes containing finely divided aluminum or iron can be oxidized so rapidly that unsafe conditions can occur - a situation common to most aqueous oxidants. 


\section{System and Integration}

Normally, bulk organic destruction is best pursued in a cascaded series of continuouslystirred tank-reactors (CSTR's). Additional peroxydisulfate may be used in the final stage as a polisher to eliminate the last traces of organic material. The resultant bisulfate or sulfate ion may be recycled to produce new oxidant by electrolysis using industrial electrolysis equipment. This recycle is not hindered by small quantities of common inorganic materials (such as nitrates, chlorides, phosphates, etc.) or by small quantities of organic residuals which might be entrained in the process stream.

Hydrolysis and Oxidation. An integrated bench-scale system for the destruction of a wide range of chlorinated organic liquids and organic-contaminated sludge has been demonstrated at LLNL. Many chlorinated solvents benefit (but do not require) hydrolysis to offset difficulties presented by their high volatility at operating temperatures of $100^{\circ} \mathrm{C}$. In pilot tests at LLNL, mixed-waste solvents based on 1,1,1-trichloroethane (TCA) were hydrolyzed at elevated temperatures $\left(\leq 150^{\circ} \mathrm{C}\right)$ (Figure 3). The products of hydrolysis, which are water-soluble and nonvolatile, were subsequently oxidized at ambient pressure in a three-stage CSTR system. (Figure 4). 
Proc. Advanced Research Workshop: Environmental Aspects of Converting CW Facilities to Peaceful Purpose March 10, 1999 Spiez Switzerland

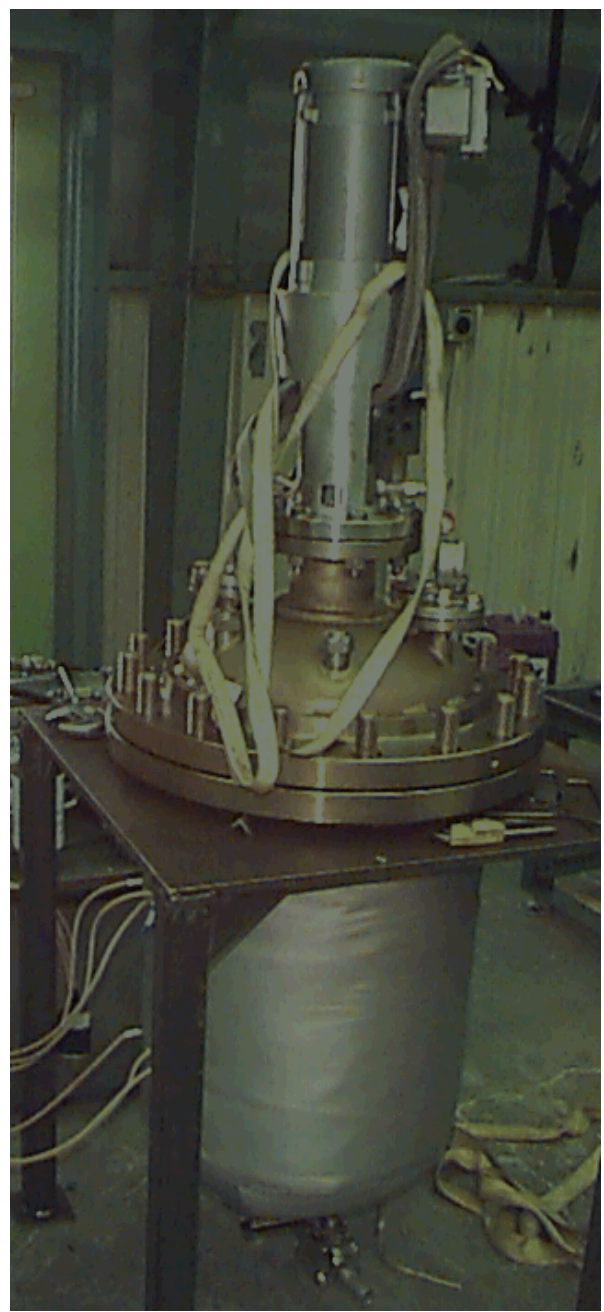

UCRL-JC-134229 Page 6

Figure 2. One of five, 2-m tall, 75-liter hydrolysis (or oxidation) vessels at LLNL's pilotscale waste treatment facility. Rapid hydrolysis of mixed-waste chloro-solvents to produce water-soluble products was demonstrated here and in same scale laboratory systems (Figure 4). 
Proc. Advanced Research Workshop: Environmental Aspects of Converting CW Facilities to Peaceful Purpose March 10, 1999 Spiez Switzerland

UCRL-JC-134229 Page 7

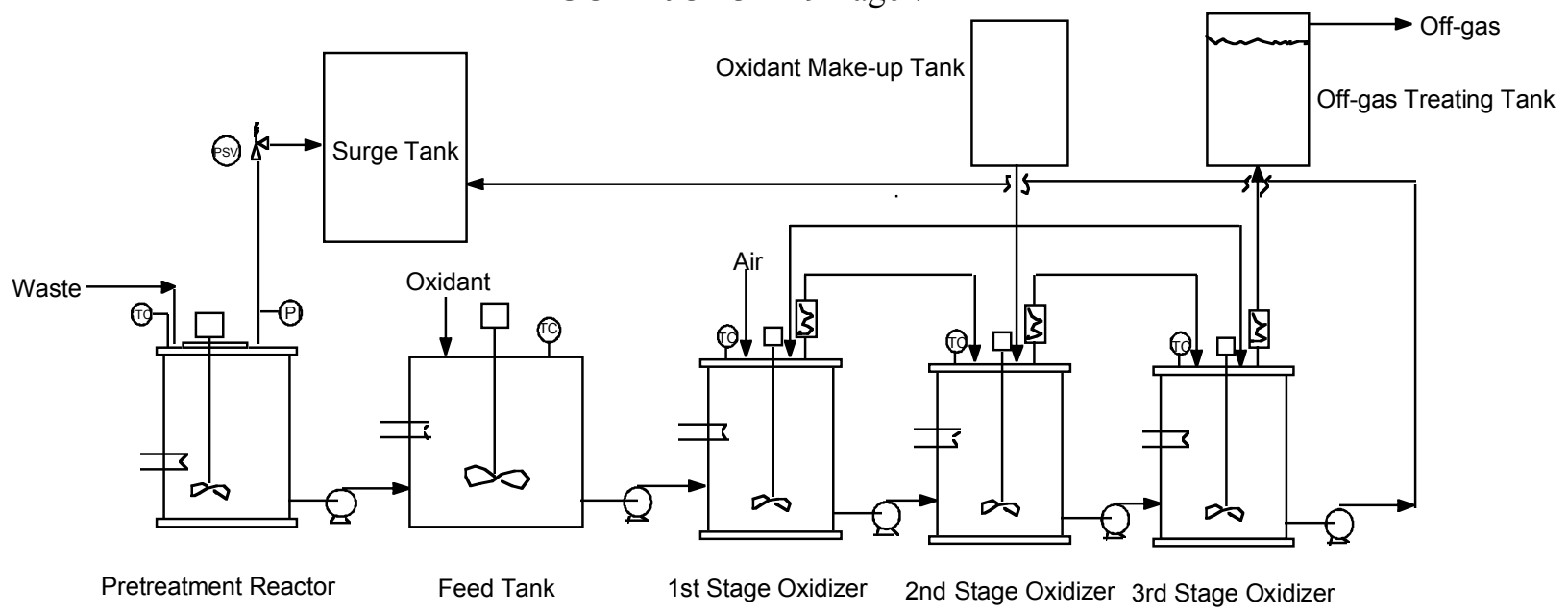

Figure 3. Schematic of pilot scale process tested at LLNL on wastes based on 1,1,1trichloroethane (methyl chloroform). Pre-hydrolysis converts very volatile chlorinated solvents to water-soluble products, which are then oxidized at atmospheric pressure in a series of three CSTR's.
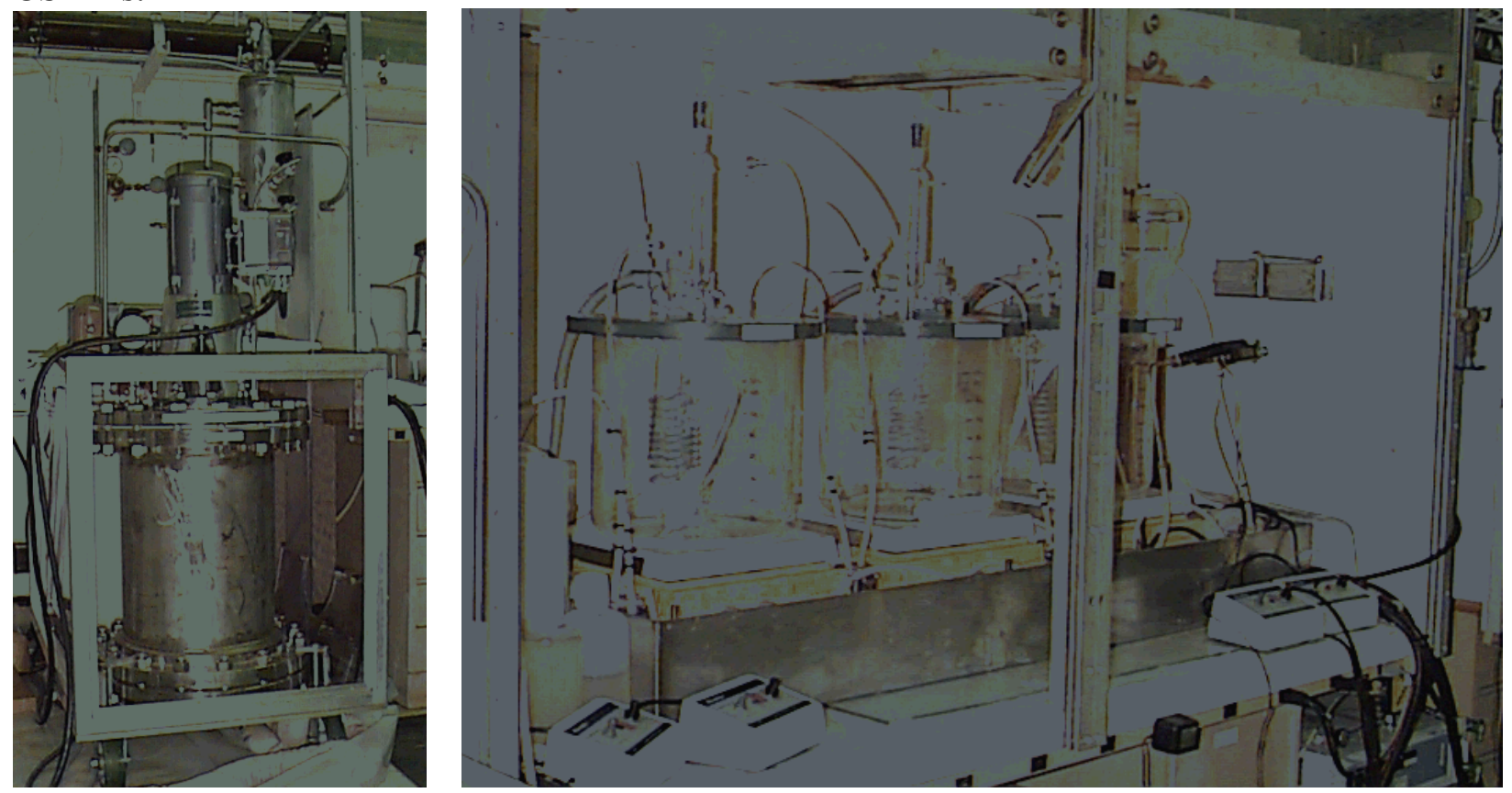

Figure 4. Pilot-scale laboratory unit used in destruction of trichloroethane (TCA) solvents, $15 \mathrm{~kg} /$ day. The 60-liter hydrolysis vessel (left) converts TCA into water-soluble species, which are oxidized in a three-stage CSTR system (right). Data from this system is presented in Table 6.

The integrated DCO process (including hydrolysis) was demonstrated on the pilot-plant scale (15 kg/day, as carbon), using LLNL waste streams or surrogates containing chlorinated solvents. A broad spectrum of materials has been successfully oxidized using peroxydisulfate, including: acetic acid, formamide, ethylene glycol, tributyl phosphate, trialkyl amines, kerosene, methyl chloroform, trinitrotoluene and other explosives, surrogates for biological or chemical 
Proc. Advanced Research Workshop: Environmental Aspects of Converting CW Facilities to Peaceful Purpose March 10, 1999 Spiez Switzerland

UCRL-JC-134229 Page 8

warfare agents, paper and cotton, PCB's, pentachlorophenol, ion exchange resins (DOWEX), and carbon residuals found in simulated sludge. Further research is not deemed necessary prior to scale-up for implementation, but treatability studies should be undertaken on each candidate waste stream to ensure processability. LLNL is pursuing commercialization of the process through a collaborative effort with waste treatment vendors and end-users; a process which would involve field treatability studies in parallel with technical and scientific support at LLNL, using the pilot plant units (Figure 3,4).

Materials of Construction and Containment. No unusual or expensive containment materials are required. Oxidation is best pursued in ceramic or glass-lined vessels, or in earthenware. Hydrolysis vessels are stainless steel. Electrolysis vessels are stainless steel, glass or earthenware; electrodes are graphite and platinum.

Offgas Composition. The composition of the offgas stream will depend on the particular waste being processed, but general predictions can be made. Common to all organic waste streams will be carbon dioxide; oxygen will also be produced by a minor, competing side reaction (oxidation of water). In acid solutions, some chlorine will be present in the offgas resulting from oxidation of chlorine-containing wastes; the chlorine may be neutralized by thiosulfate. The use of DCO in alkaline solutions avoids the formation of chlorine and chlorine released from organic molecule or free inorganic chloride remains as the chloride ion in solution. In cases where the oxidant is recycled by electrolysis, then oxygen, ozone, and possibly chlorine (if chloride is present) will be added to the anode offgas. In industrial electrolysis cells, the hydrogen gas is concurrently produced at the cathode; this gas may be oxidized to water (in a catalyzed bed) and the water internally recycled. Commercial catalysts are available for this purpose.

Because of the low volume of offgas (essentially only the carbon dioxide fraction and water vapor), the offgas can be captured and retained if volatile radionuclides (tritium) or heavy metals (mercury) are present in the waste. At the process operating conditions, formation of dioxins and furans in the offgas is not believed possible, and analyses to check for these materials have been negative.

\section{Performance and Experimental Results}

The oxidation proceeds at a rate of about $200 \mathrm{~kg}$ (as carbon) per cubic meter of reaction vessel per day. This rate can be derived directly from a $\mathrm{k}_{\mathrm{a}}$ of $0.02-0.04 \mathrm{~min}^{-1}$ and an input concentration of $5 \mathrm{~N}$ oxidant. This number can be used as a rough estimate for batch and CSTR scaling. Rates of destruction of solids can be lower if the reaction is transport or surface-kinetics limited, as in the case of some plastics or amorphous carbon. Performance can best be described by a series of examples:

Bulk rates for concentrated wastes. Table 2 summarizes rate data for various surrogate wastes, representing important waste streams. The percentage destroyed at the given rate is presented. 
Proc. Advanced Research Workshop: Environmental Aspects of Converting CW Facilities to Peaceful Purpose March 10, 1999 Spiez Switzerland

UCRL-JC-134229 Page 9

Oxidation time profiles. Table 3 follows the destruction of kerosene following introduction of the oxidant at $90^{\circ} \mathrm{C}$. The data illustrates the rapid destruction of material from the initial concentration, followed by slower reaction of the very dilute solution.

Oxidation of chlorosolvents without hydrolysis. Table 4 summarizes data on treatment of chlorinated solvents in sealed vessels, without hydrolysis pretreatment. It is emphasized that chlorinated materials are readily destroyed by peroxydisulfate. Pre-hydrolysis avoids the requirements for pressurizing the oxidation step (with $\mathrm{CO}_{2}$ evolution) to avoid entrainment of the volatile solvents in the $\mathrm{CO}_{2}$ offgas.

Destruction of $P C B$ 's. Table 5 presents results of treatment of PCB's in very dilute solutions, with and without a hydrolysis pretreatment. Here, hydrolysis is not necessary as PCB's are not volatile, and therefore little is gained by the pretreatment. Pentachlorophenol is also fully oxidized in basic DCO media. Work is in progress to determine rates of destruction of high concentrations of PCB's ( $2 \%$ in oils).

Scale-up of hydrolysis and oxidation of methyl chloroform. In Table 6, the results of pilotscale testing of DCO on the destruction of trichloroethane (methyl chloroform) in a two step process: base hydrolysis in a 60 Liter vessel followed by oxidation in a CSTR system (consisting of three 15 liter vessels). The products of hydrolysis are fully destroyed, in good agreement with a process model based on equation 2 . This work establishes that the process scales well from bench top equipment to pilot scale (i.e., $15 \mathrm{~kg}-\mathrm{C} / \mathrm{day}$ ).

Table 2. Oxidation rates (scale factors) for compounds at high concentrations.

\begin{tabular}{|l|c|c|}
\hline Compound & Rate, $\mathrm{kg} / \mathrm{m} 3$-day & Percentage destroyed at rate \\
\hline $2,4,6$-trinitrotoluene & 132 & $>98.8$ \\
\hline Kerosene & 186 & $>99.97$ \\
\hline Triethylamine & 205 & $>98.8$ \\
\hline Dowex & 132 & $>99$ \\
\hline Ethylene glycol & 432 & $>99.93$ \\
\hline
\end{tabular}

Table 3. Oxidation of kerosene (predominately dodecane) at $90{ }^{\circ} \mathrm{C}$.

\begin{tabular}{|c|c|c|c|c|}
\hline Time, min & $\begin{array}{c}\text { Oxidant added, } \\
\text { Equivalents }\end{array}$ & $\begin{array}{c}\text { Carbon } \\
\text { determinations, } \\
\text { ppm-Wt C }\end{array}$ & Residual Carbon, g-C & Destruction extent, \% \\
\hline 0 & 0 & 59060 & 3.17 & 0 \\
\hline 70 & 1.4 & 1.3 & 0.00073 & 99.97 \\
\hline 140 & 2.8 & 0.27 & 0.00029 & 99.99 \\
\hline
\end{tabular}

Table 4. Oxidation of Chloro-solvents by peroxydisulfate in sealed vessels.

\begin{tabular}{|l|c|}
\hline \multicolumn{1}{|c|}{ Chloro-solvent } & Extent of oxidation after 1 hour \\
\hline Perchloroethylene & 0.991 \\
\hline Trichloroethylene & 0.996 \\
\hline methylene chloride & 0.991 \\
\hline Chloroform & 0.967 \\
\hline Perchloroethylene/chloroform mixtures (50\%) & 0.991 \\
\hline
\end{tabular}


Proc. Advanced Research Workshop: Environmental Aspects of Converting CW Facilities to Peaceful Purpose March 10, 1999 Spiez Switzerland

UCRL-JC-134229 Page 10

Table 5. Results of DCO treatment of low concentrations of PCB's (45 ppm Arochlor 1242) by oxidation in basic media, and by oxidation following hydrolysis pretreatment. Analysis is by EPA method 608; Analysis by Centre Analytical, Inc.; *corresponds to limit of detection. Values are in microgram/L (ppb).

\begin{tabular}{|c|c|c|c|c|}
\hline Compound & $\begin{array}{r}\text { Excess } \\
85 \\
\end{array}$ & $\begin{array}{l}: \\
\mathrm{I} \mathrm{NaOH} \\
\mathrm{hr}\end{array}$ & $\begin{array}{c}4.5 \mathrm{~h} \text { hydrolysis, } \\
100^{\circ} \mathrm{C} \\
\text { oxidation for } 1 \mathrm{hr}\end{array}$ & $\begin{array}{c}48 \mathrm{hr} \text { hydrolysis, } \\
100^{\circ} \mathrm{C} \\
\text { oxidation for } 1 \mathrm{hr}\end{array}$ \\
\hline monochlorobiphenyl & $<0.65^{*}$ & $<0.5^{*}$ & $<0.5^{*}$ & $<0.5^{*}$ \\
\hline dichlorobiphenyl & $<0.65^{*}$ & $<0.5^{*}$ & $<0.5^{*}$ & 3.47 \\
\hline trichlorobiphenyl & $<0.65^{*}$ & $<0.5^{*}$ & $<0.5^{*}$ & 2.37 \\
\hline tetrachlorobiphenyl & $<1.3^{*}$ & $<1.0^{*}$ & $<1.0^{*}$ & 7.08 \\
\hline pentachlorobiphenyl & $<1.3^{*}$ & $<1.0^{*}$ & $<1.0^{*}$ & $<1.0^{*}$ \\
\hline hexachlorobiphenyl & $<1.3^{*}$ & $<1.0^{*}$ & $<1.0^{*}$ & $<1.0^{*}$ \\
\hline heptachlorobiphenyl & $<1.9^{*}$ & $<1.5^{*}$ & $<1.5^{*}$ & $<1.5^{*}$ \\
\hline octachloro-biphenyl & $<1.9^{*}$ & $<1.5^{*}$ & $<1.5^{*}$ & $<1.5^{*}$ \\
\hline decachlorobiphenyl & $<3.2^{*}$ & $<2.5^{*}$ & $<2.5^{*}$ & $<2.5^{*}$ \\
\hline
\end{tabular}

Table 6. Experimental and theoretical destruction of waste (base-hydrolyzed trichloroethane) in three-stage CSTR $T=90 \mathrm{C} ; \mathrm{V}=15$ liters per vessel; flow $=0.10$ liter/min; process model: rate $=\mathrm{k}_{\mathrm{a}}\left[\mathrm{S}_{\mathbf{2}} \mathrm{O}_{\mathbf{8}}{ }^{2-}\right]$

\begin{tabular}{|l|c|c|}
\hline Parameter & Experimental & Process Model \\
\hline Concentration of waste input & $0.11 \mathrm{M}$ & $(0.11 \mathrm{M})$ \\
\hline CSTR \#1 output & $0.0061 \mathrm{M}$ & $0.00701 \mathrm{M}$ \\
\hline cumulative efficiency & $94.45 \%$ & $93.6 \%$ \\
\hline CSTR \#2 & $0.0006 \mathrm{M}$ & $0.0005 \mathrm{M}$ \\
\hline cumulative efficiency & $99.46 \%$ & $99.59 \%$ \\
\hline CSTR \#3 & $0.0003 \mathrm{M}$ & $0.00003 \mathrm{M}$ \\
\hline cumulative efficiency & $99.76 \%$ & $99.97 \%$ \\
\hline
\end{tabular}

\section{Technology Applicability and Benefits}

Applicability. DCO is capable of oxidizing nearly any organic solid or liquid contaminant under practical operating conditions $\left(\mathrm{T}<100^{\circ} \mathrm{C}\right.$, ambient pressure). Specific wastes tested successfully include: solvents, including chloro-solvents; detergents, pesticides, and chemical warfare agents biologic materials; water-insoluble oils and greases; filter media, chars and tars paper and cotton; chlorinated, sulfated, nitrated, and phosphorus-containing wastes organics contaminants immobilized in organic/inorganic matrices such as soil, sands, sludge, or porous solids.

In addition to bulk waste destruction, the process is particularly attractive for surface etching and decontamination of metal (including ferrous, brass, copper, stainless steel) ceramic, or plastic debris. Peroxydisulfate has also been used alone or with a $\mathrm{Ag}$ (II) catalyst in decontamination and etching solutions for removing $\mathrm{PuO}_{2}$ (as dissolved plutonyl ion) from nuclear equipment. 
Proc. Advanced Research Workshop: Environmental Aspects of Converting CW Facilities to Peaceful Purpose March 10, 1999 Spiez Switzerland

UCRL-JC-134229 Page 11

Rates. For nearly all organic liquids, the rate of destruction at $90-100^{\circ} \mathrm{C}$ is roughly $200 \mathrm{~kg}$ (as carbon) per cubic meter of reaction vessel per day. This near constancy of rate reflects the common rate limiting step of the formation of the sulfate radical anion, $\mathrm{SO}_{4}{ }^{-}$

Benefits. DCO uses solutions of the peroxydisulfate ion, the strongest known chemical oxidant other than fluorine-based chemicals, to convert organic solids and liquids to carbon dioxide, water, and constituent minerals. The expended oxidant may be electrolytically regenerated to minimize secondary wastes. Offgas volumes are minimal, allowing retention of volatile or radioactive components. Among the benefits and limitations of the DCO technology, are:

1. DCO can treat a wide variety of organic wastes (liquids and solids; water-soluble or not) and waste matrices (soils, sands, clays; ceramic substrates; steel machinery, etc.) contaminated with organic constituents.

2. Process operation and control is simple; scale-up or scale-down is straightforward; and common materials of construction are used (such as polymer- or glass-lined steel, earthenware, or stainless steel).

3. The speed of the oxidation reaction can be selected (through concentrations and temperature) to provide either complete destruction of organic substrates, or merely decontamination and etching of metal, ceramic or plastic debris.

4. Peroxydisulfate oxidation generates no toxic byproducts, and the oxidation product (sulfate) can be recycled--thereby reducing oxidant costs and minimizing secondary wastes.

5. The non-thermal process operates below $100^{\circ} \mathrm{C}$, thus minimizing the offgas volume, and precluding the potential for formation of dioxins and furans in the offgas and reducing the requirements and offgas treatment costs.

6. The process is probably most attractive when a small amount of organic must be removed from a large amount of an inert solid matrix, such as sludge, soil, sand or filter material. Decontamination is similarly well suited, using peroxydisulfate alone or with a mediated chemical oxidant couple such as $\mathrm{Ag}(\mathrm{I}) / \mathrm{Ag}(\mathrm{II}), \mathrm{Ce}(\mathrm{III}) / \mathrm{Ce}(\mathrm{IV})$, or $\mathrm{Co}(\mathrm{II}) / \mathrm{Co}(\mathrm{III})$.

\section{Preliminary Cost Analysis}

The cost of organic-waste destruction using the DCO technology is directly related to the carbon content, matrix of the waste stream being treated, and whether or not the expended oxidant is recycled. On a per pound of carbon basis, obviously costs are lowest when treating oxidizable organics in concentrated liquid form or when dispersed in an essentially non-reactive matrix such as sandy soil or sludge. Costs will be higher for heavily chlorinated wastes, or if the waste contains a substantial amount of non-hazardous organics (such as humic acid in contaminated soils, or cotton rags or paper in undifferentiated wastes).

For destruction of organics, whether neat or in matrix, the cost can be estimated using the following values. 
Proc. Advanced Research Workshop: Environmental Aspects of Converting CW Facilities to Peaceful Purpose March 10, 1999 Spiez Switzerland

UCRL-JC-134229 Page 12

Table 7. DCO Cost Factors and assumptions for $50 \mathrm{~kg}-\mathrm{C} / \mathrm{day}$ (waste measured in terms of weight of carbon content)

\begin{tabular}{|l|c|c|}
\hline \multicolumn{1}{|c|}{ Factor } & Basis & Value \\
\hline 1. Cost of peroxydisulfate purchased bulk & Bulk, $\$ 0.73 / \mathrm{lb} ; 3 \mathrm{~g}-\mathrm{C} /$ equivalent & $\$ 79 / \mathrm{kg}$-C \\
\hline 2. Equivalent weight of carbon & $\mathrm{C}+\mathrm{O}_{2}=>\mathrm{CO}_{2}$ & $0.003 \mathrm{~kg} / \mathrm{equivalent}$ \\
\hline 3. Destruction stoichiometric efficiency & Measured & $80 \%$ \\
\hline 4. Electrolysis cell voltage & Industrial value & $4 \mathrm{~V}$ \\
\hline 5. Electrolysis efficiency & Industrial & $80 \%$ \\
\hline 6. Cost of electrical energy & $\$ 0.06 / \mathrm{kWh} ; 4 \mathrm{~V} ; 80 \%$ efficiency; 3-g-C/equiv & $\$ 2.68 / \mathrm{kg}-\mathrm{C}$ \\
\hline 7. Labor cost for destruction and recycle & $\$ 120 /$ day; $80 \%$ capacity factor & $\$ 3 / \mathrm{kg}$-C \\
\hline 8. Capital amortization & $\begin{array}{c}\$ 100,000 ; 6 \text { years; } 15 \% \text { interest; } 80 \% \text { capacity } \\
\text { factor }\end{array}$ & $\$ 1.92 / \mathrm{kg}-\mathrm{C}$ \\
\hline 9. Profit and G\&A & & $30 \%$ \\
\hline
\end{tabular}

If the expended oxidant is not recycled, then the cost of DCO is $\$ 79 / \mathrm{kg}$ of carbon in the waste. This is calculated from the equivalent weights of sodium peroxydisulfate (119 $\mathrm{g} /$ equivalent) and carbon ( $3 \mathrm{~g} /$ equivalent), the bulk cost of the sodium peroxydisulfate $(\$ 0.73 / \mathrm{lb})$, and an assumed $80 \%$ stoichiometric efficiency: $\$ 79 / \mathrm{kg}-\mathrm{C}=(\$ 0.73 / 454 \mathrm{~g})(119 \mathrm{~g} / 3 \mathrm{~g}-\mathrm{C})(1 / 0.8)$. Purchased peroxydisulfate would be used when recycle is either too complex or too expensive to be cost-effective, such as when the concentration of organic material in the matrix is very small and the contribution of the product sulfate to secondary waste is negligible.

If the product sulfate is to be recycled to produce new oxidant, then the cost and complexity of the electrolysis plant must be considered versus the cost of new chemical. The cost of the process including recycling is the sum of electrical energy, labor and capital $(\$ 2.68+\$ 3+\$ 1.92)$ estimated for a plant operating at $80 \%$ capacity factor and scaled for 50 $\mathrm{kg} /$ day, increased by $30 \%$ profit and GSA: $\$ 9.88 / \mathrm{kg}$-carbon content.

In cases where a small amount of organic material is entrained in a large amount of inorganic waste (including water), the cost benefit of recycling is likely to be very small. In cases where the organic waste is highly concentrated, recycling is necessary because chemical costs and the sulfate contribution to secondary wastes become significant.

These estimates are crude, and do not include costs of working in a nuclear environment, special costs of pretreatment, (i.e. sorting, segregating, or sizing operations, and hydrolysis), and stabilization and disposition of the final product.

\section{Safety Considerations}

Direct Chemical Oxidation technology exhibits hazards typical of many industrial treatment and chemical synthesis operations. To its advantage, the process does not require the use of high voltage or amperage, generates no toxic or explosive gases. However, the use of strong oxidants at slightly elevated temperatures can lead to worker safety concerns if the proper engineering and administrative controls are not established. Proper design and use of established procedures should mitigate of these risks. Critical to a safe design is material selection to avoid 
Proc. Advanced Research Workshop: Environmental Aspects of Converting CW Facilities to Peaceful Purpose March 10, 1999 Spiez Switzerland

UCRL-JC-134229 Page 13

corrosion and potential breech of primary containment. In addition, procedures must address methods and monitoring required to avoid reaction rate excursions leading to rapid temperature and pressure increases. Feed rate control of easily oxidized materials and/or highly reactive organics is of particular concern. Aluminum, iron and zinc powders, metallic alkali metals, lithium hydride, and sodium oxide should be removed from DCO feeds as they should from essentially all oxidizing aqueous solutions. In addition, dry sodium peroxydisulfate must be handled per the applicable safety protocol and stored separately from reducible materials, but as used, in relatively dilute aqueous solutions, and contained in ceramic, earthenware or glass-lined vessels, reactions are predictable and readily controlled. The DCO process is typically operated with acidic process solutions, but for certain applications, basic operation is desirable. For example, at elevated values of $\mathrm{pH}$, iron is readily passivated, and chlorine is retained in solution as chloride ion, thus keeping it out of the vapor stream leaving the reactor(s).

Technology Limitations and Needs for Future Development. As mentioned previously, the DCO process was developed to destroy a wide variety of regulated organic materials. It is well suited to the destruction of most liquid organics, though some may require a hydrolysis step to enhance miscibility in water and/or decrease vapor pressure. The process can also destroy cellulose debris and dispersed organic contamination in an essentially inert inorganic matrix such as sandy soil or metallic debris, with the potential to provide excellent decontamination of most debris. However, applications to large quantities of bulk organic matter or combustible debris will require large amounts of oxidant which will contribute to secondary wastes or will require significant recycle. Incineration will probably be a more cost-effective choice for these wastes.

Though the process chemistry is relatively well defined, operations to date have been conducted in carefully controlled laboratory conditions and operating experience is needed. It is also acknowledged that treatability studies will be required for any new waste stream. Sufficient performance data is also needed to support a RCRA permit application. In addition, the operating envelope must be better defined to support design of ancillary systems for feed sorting, segregating and sizing, and oxidant recycle and recovery systems.

\section{Acknowledgments}

Work performed under the auspices of the U.S. Department of Energy by the Lawrence Livermore National Laboratory under contract number W-7405-ENG-48.

We gratefully acknowledge support by the Mixed Waste Focus Group of the U.S. Department of Energy.

This report is abstracted from and contains essential information from a report prepared for the U.S. Department of Energy, Office of Environmental Management, Office of Science and Technology "Innovative Technology Summary Report: Direct Chemical Oxidation, An Alternative Oxidation Technology;" September 1998. 
Proc. Advanced Research Workshop: Environmental Aspects of Converting CW Facilities to Peaceful Purpose March 10, 1999 Spiez Switzerland

UCRL-JC-134229 Page 14

\section{References}

1. John F. Cooper, F. Wang, J. Farmer, R. Foreman, T. Shell and K. King, "Direct Chemical Oxidation of Hazardous and Mixed Wastes" (Proceedings. of the Third Biennial Mixed Waste Symposium, American Society of Mechanical Engineers; Aug. 1995); Lawrence Livermore National Laboratory Report UCRL-JC-120141 March 28, 1995.

2. John F. Cooper, F. Wang, J. Farmer, M. Adamson, K. King and R. Krueger, "Direct Chemical Oxidation: Peroxydisulfate destruction of organic wastes," Proceedings World Environmental Congress, International Conference and Trade Fair, Page 219; London Ontario Sept. 17-22 1995.

3. F. Wang, J. F. Cooper, J. Farmer, M. Adamson and T. Shell, "Destruction of ion exchange resins by wet oxidation and by direct chemical oxidation--a comparison study," Proceedings World Environmental Congress, International Conference and Trade Fair, p. 206; London Ontario Sept. 17-22 1995.

4. John F. Cooper, Francis Wang, Roger Krueger, Ken King, Joseph C. Farmer, and Martyn Adamson, "Destruction of organic wastes by ammonium peroxydisulfate with electrolytic regeneration of the oxidant," LLNL Internal Report, September 1995. UCRL-121979 Rev 1 October 10, 1995.

5. John F. Cooper, Roger Krueger and Joseph C. Farmer, "Destruction of VX by aqueousphase oxidation using peroxydisulfate: Direct chemical oxidation," (Proceedings Workshop on Advances in Alternative Demilitarization Technologies, pp. 429-442; Reston VA September 25-7 1995; published by SAIC Aberdeen, MD)

6. John F. Cooper, Francis Wang, Roger Krueger, Ken King, Thomas Shell, Joseph C. Farmer, and Martyn Adamson, "Demonstration of omnivorous non-thermal mixed waste treatment: Direct chemical oxidation using peroxydisulfate," First Quarterly Report to Mixed Waste Focus Group, SF2-3-MW-35 October - December 1995; UCRL-ID-123193, February 1996.

7. John F. Cooper, Francis Wang Thomas Shell, and Ken King, "Destruction of 2,4,6trinitrotoluene using ammonium peroxydisulfate," LLNL Report UCRL-ID-124585, July 1996.

8. John F. Cooper, Francis Wang, Roger Krueger and Ken King, "Destruction of organic wastes with electrolytic regeneration of the oxidant," Proceedings Sixth International Conference on Radioactive Waste Management and Environmental Remediation, Singapore October 12-16 1997. UCRL-JC--121979 rev 2 July 1997.

9. House, D. A., Chem. Rev. 196162185.

10. Minisci, F., , A.C., and Giordano, C.; Acc. Chem. Res.1983 1627. 
Proc. Advanced Research Workshop: Environmental Aspects of Converting CW Facilities to Peaceful Purpose March 10, 1999 Spiez Switzerland

UCRL-JC-134229 Page 15

11. Gary Peyton, Marine Chemistry 41 91-103 (1993).

12. J. Richard Pugh, John H. Grinstead, Jr., James A. Farley, and James L. Horton "Degradation of PCB's and atrazine by peroxydisulfate compounds," Proc. World Environmental Congress, International Conference and Trade Fair, London Ontario, September 171995 